\title{
Commentary: One more option in the conundrum of choice of aortic valve bioprostheses
}

Vito Domenico Bruno, $\mathrm{PhD}$, and Umberto Benedetto, $\mathrm{PhD}$

From Translational Health Science, Bristol Medical School, University of Bristol, Bristol, United Kingdom.

Disclosures: Authors have nothing to disclose with regard to commercial support.

Received for publication Aug 6, 2019; revisions received Aug 6, 2019; accepted for publication Aug 7, 2019; available ahead of print Sept 19, 2019.

Address for reprints: Umberto Benedetto, PhD, Bristol Medical School, Translational Health Sciences, University of Bristol, Research Floor Level 7, Bristol Royal Infirmary, Upper Maudlin St, BS2 8HW Bristol, United Kingdom (E-mail: umberto.benedetto@bristol.ac.uk).

J Thorac Cardiovasc Surg 2020;160:384

$0022-5223 / \$ 36.00$

Copyright $(2019$ by The American Association for Thoracic Surgery

https://doi.org/10.1016/j.jtcvs.2019.08.064

In their article in this issue of the Journal, Dagenais and colleagues ${ }^{1}$ present the 2-year results of the PERIcardial SurGical AOrtic Valve ReplacemeNT (PERIGON) pivotal trial. This study is a prospective, nonrandomized international multicenter trial that aims to evaluate the safety and effectiveness of the Avalus bovine pericardial valve (Medtronic, Minneapolis, Minn) in the aortic position. The use of the Avalus valve was associated with good clinical results, as demonstrated by low mortality, low valve-related adverse event rates, and improved functional class for most patients. Dagenais and colleagues ${ }^{1}$ found an increased rate of bleeding in comparison with the expected rate of bleeding reported for other bioprosthetic valves, ${ }^{2}$ but this is likely related not directly to the valve but rather to the use of oral anticoagulation during the first 6 to 12 months after surgery.

One aspect however, merits further attention: in the current series of Dagenais and colleagues, ${ }^{1}$ the rates of moderate and severe patient-prosthesis mismatch (PPM) are particularly high, at $43.5 \%$ and $34.8 \%$, respectively. Moreover, $64.6 \%$ of the patients with severe PPM had a $23-\mathrm{mm}$ or larger valve implanted. Dagenais and colleagues ${ }^{1}$ have investigated the effect of small effective orifice area (EOA) by means of a fitted joint model, which did not demonstrate an association between the $\log$ of EOA and mortality. On the basis of these results, Dagenais and colleagues ${ }^{1}$ concluded that the Avalus valves provide adequate EOA. It could be argued that the lack of an association between EOA and survival is likely to be related to the very short follow-up duration of the current series. Previous studies ${ }^{3,4}$ have consistently shown that the occurrence of severe PPM after surgical aortic valve replacement is associated with increased risks of death and congestive heart failure. The effect on long-term outcomes of a high PPM rate with Avalus valves require further investigation. On the other hand, the valve was demonstrated to be associated with very low rate of perivalvular leak, and Dagenais and

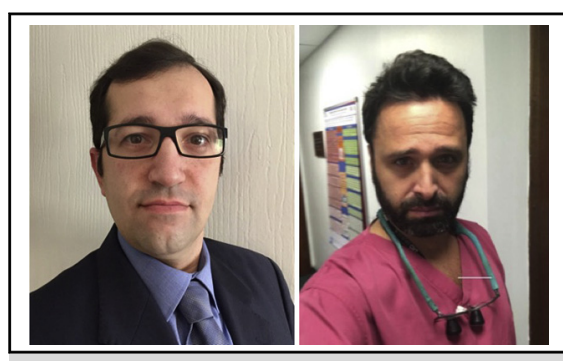

Vito Domenico Bruno, PhD (left), and Umberto Benedetto, PhD (right)

Central Message

The early results of the PERIGON trial demonstrate the safety and efficacy of the new Avalus aortic valve (Medtronic, Minneapolis, Minn), but what about the long term?

See Article page 371 .

colleagues $^{1}$ suggest that this might be due to the generous cuff of the valve. It could be argued that a large cuff might also be at least partially responsible for the smaller EOA, and thus for the increased incidence of PPM. The current research presented by Dagenais and colleagues ${ }^{1}$ is an industry-funded study, and this aspect may be a cause of distress for some readers. This is a US Food and Drug Administration-approved trial, though, and its results are demonstrating excellent short-term outcomes after Avalus valve implantation. This short follow-up duration, however, prevents us from drawing final conclusions as to the safety and durability of the Avalus valve, and longer-term followup is needed.

\section{References}

1. Dagenais F, Moront MG, Brown WM, Reardon MJ, Chu MWA, Gearhart E, et al Safety, efficacy, and hemodynamic performance of a stented bovine pericardial aortic valve bioprosthesis: two-year analysis. J Thorac Cardiovasc Surg. 2020; 160:371-81.e4.

2. Klautz RJM, Kappetein AP, Lange R, Dagenais F, Labrousse L, Bapat V, et al; PERIGON Investigators. Safety, effectiveness and haemodynamic performance of a new stented aortic valve bioprosthesis. Eur J Cardiothorac Surg. 2017;52: 425-31.

3. Zorn GL III, Little SH, Tadros P, Deeb GM, Gleason TG, Heiser J, et al. Prosthesispatient mismatch in high-risk patients with severe aortic stenosis: a randomized trial of a self-expanding prosthesis. J Thorac Cardiovasc Surg. 2016;151: 1014-23.e3.

4. Finkelstein A, Schwartz AL, Uretzky G, Banai S, Keren G, Kramer A, et al. Hemodynamic performance and outcome of percutaneous versus surgical stentless bioprostheses for aortic stenosis with anticipated patient-prosthesis mismatch. J Thorac Cardiovasc Surg. 2014;147:1892-9. 